\title{
Aqueous degradation kinetics of pharmaceutical drug diclofenac by photocatalysis using nanostructured titania-zirconia composite catalyst
}

\author{
L. Das - S. K. Barodia - S. Sengupta • \\ J. K. Basu
}

Received: 20 November 2012/Revised: 2 October 2013/ Accepted: 7 December 2013/Published online: 8 January 2014

(C) Islamic Azad University (IAU) 2013

\begin{abstract}
Diclofenac (DCF) is an anti-inflammatory pharmaceutical drug, and its presence in a trace amount in waste water makes severe environmental pollution. The degradation of DCF was investigated by a photocatalytic process in presence of ultra violet irradiation at room temperature using titania and titania-zirconia nanocomposite catalysts in a batch reactor. The composite catalyst was prepared by sol-gel method and characterized by $\mathrm{X}$-ray diffraction, transmission electron microscopy as well as BET surface area analyzer. The effect of various process parameters such as catalyst loading, initial concentration of DCF and $\mathrm{pH}$ of the experimental solution was observed on the degradation of DCF. The titania-zirconia nanocomposites exhibited reasonably higher photocatalytic activity than that of anatase form of titania without zirconia. The maximum removal of DCF of about $92.41 \%$ was achieved using $\mathrm{Zr} / \mathrm{Ti}$ mass ratio of $11.8 \mathrm{wt} \%$ composite catalyst. A rate equation was proposed for the degradation of DCF using the composite catalyst. The values of rate constant $\left(k_{\mathrm{c}}\right)$ and adsorption equilibrium constant $\left(K_{1}\right)$ were found to vary with the catalyst content in the reaction mixture.
\end{abstract}

Keywords Nanocomposite catalyst - Photodegradation . Diclofenac $\cdot$ Kinetic model

L. Das · S. K. Barodia · S. Sengupta · J. K. Basu $(\bowtie)$

Department of Chemical Engineering, Indian Institute of

Technology Kharagpur, Kharagpur 721302, India

e-mail: jkbosu@gmail.com; jkb@che.iitkgp.ernet.in

\section{Introduction}

In current scenario, pharmaceutical residues in the aquatic environment have become one of the major concerns in the light of environmental protection. Their continuous disposals, which may be direct or indirect, may cause substantial increase of the undesired contaminants in the aquatic environment (Schmidt et al. 2011). Mostly, the design drugs have stable chemical structures for long-term therapeutic work which persist long enough in the aquatic environment (Cunningham et al. 2009), and many of the residual drugs carried with the pharmaceutical industrial effluents are not biodegradable and pass through the potable water system (Ternes 1998).

Diclofenac (DCF) is an anti-inflammatory pharmaceutical drug, and its presence in a trace amount in water bodies has become an important issue from the human health and environmental risks point of view due to its toxic properties. DCF commonly known as Voltaren, a non-steroidal anti-inflammatory drug has worldwide market in veterinary and human pharmaceutical industries. It has extensive use as analgesic, anti-arthritic and antirheumatic and becomes one of the common pharmaceutical contaminants in aquatic system (Leztel et al. 2009). It is commonly detected in effluent of sewage treatment plants and surface water in countries such as Brazil, UK, etc. (Stumpf et al. 1999; Ashton et al. 2004). Adverse effect of DCF contamination on vulture and aquatic species can be noticed, as declination in populations of vultures in the Indian subcontinent (Shulzt et al. 2004) and Southern African wild (Naidoo et al. 2009) and decrease in reproduction of fish (Lee et al. 2011).

Advanced oxidation processes (AOPs) have been considered as an effective way to degrade wide variety of contaminants such as organic and inorganic compounds, 
dyes and pharmaceuticals. Efficiency of AOPs mainly depends upon the process ability to generate hydroxyl radicals (Stasinakis 2008; Laoufi et al. 2008). Therefore, AOPs followed by inexpensive biological processes show an attractive way from economical point of view. Heterogeneous photocatalytic oxidation is one of the best methods for degradation of organic pollutants. Photocatalytic oxidation shows promise for volatile organic compounds (VOCs) from smaller sources, such as wastewater treatment plants, dry-cleaning facilities, painting facilities, carbon regeneration plants, air-stripping towers, soil venting processes, hazardous waste incinerators and municipal landfills (Henschel 1998). It can also be applied to reduce VOCs as air pollutants and indoor air pollutants at ambient temperatures and pressures (Jacoby et al. 1996). It has also good impact on degradation of biological pathogens such as bacteria and viruses (Cho et al. 2001). Rather than simply transferring contaminants from one medium to another, photocatalytic oxidation systems can convert VOCs completely to $\mathrm{H}_{2} \mathrm{O}$ and $\mathrm{CO}_{2}$, leaving no harmful by-products (Evgenidou et al. 2006; Kaneco et al. 2006). It has been observed that in photocatalytic reaction, the addition of air bubble during the reaction increases the agitation in the reaction mixture. This enhances the proper absorption of the intensity of light by the catalyst particles, and the mass transfer coefficient between solute and catalyst particle increases. In heterogeneous photocatalysis, also dispersed solid particles absorb the photoenergy and generate the hydroxyl radicals in situ from dissolved oxygen or water or supplying air (Shi-fu and Xue-li 1998; Shi-fu and Geng-yu 2003). The absorption of oxygen by the surface of solution is sufficient for the photocatalytic oxidation. Among the various advanced photocatalysts were employed in different AOPs, titania $\left(\mathrm{TiO}_{2}\right)$ is the most attractive for environmental applications due to its non-toxic nature, chemical stability, insolubility in the medium, low cost and high photocatalytic activity (Chen et al. 2004). However, the higher band gap of $\mathrm{TiO}_{2}$ makes the constrain to absorb only the ultraviolet ranges $(\lambda<387 \mathrm{~nm})$ of sunlight spectrum (Tian-hua et al. 2004). To improve the photocatalytic efficiency of $\mathrm{TiO}_{2}$ catalyst, range $(\lambda>400 \mathrm{~nm})$ of sunlight absorption, coupling of two semiconductors, transition metal doping and addition of noble metals are the important parameters (Linsebigler et al. 1995). Incorporation of transition metals usually halts the photocatalytic activity of $\mathrm{TiO}_{2}$, although for some transition metals, doping enhances the photocatalytic activity (Akpan and Hameed 2010; Zaleska 2008).

Zirconium has similarity with titanium since both belong to the same group (IV) of periodic table (Vishwanathan et al. 2004; Wv et al. 1984). The incorporation of zirconia $\left(\mathrm{ZrO}_{2}\right)$ ion into $\mathrm{TiO}_{2}$ led to nanosize particles, increase in surface area and acceleration of surface hydroxylation with anatase structure, which resulted in the higher photocatalytic activity as compared to pure $\mathrm{TiO}_{2}$ (Zhang and Zeng 2010; Wang et al. 2004; Venkatachalam et al. 2007). Relative to pure $\mathrm{TiO}_{2}$, the $\mathrm{ZrO}_{2}$-doped composite had greater visible light absorption and a band gap reduction of $0.2 \mathrm{eV}$ (Qiu and Starr 2007). Photocatalytic efficiency of the catalyst strongly depends on operating parameters as the catalyst type, substrate concentration, catalyst loading, initial $\mathrm{pH}$, oxidizing agents and temperature at which the catalysts must be calcined and light intensity (Akpan and Hameed 2009; Guettai and Amar 2005; Wang et al. 2000; Hoffmann et al. 1995; Qourzal et al. 2008).

An exhaustive study on the heterogeneous photocatalytic degradation of DCF over $\mathrm{TiO}_{2}$ in presence of UV-A irradiation was done with emphasis on the effect of catalyst type, initial DCF concentrations, photocatalyst loading and $\mathrm{H}_{2} \mathrm{O}_{2}$ as an additional oxidant (Achilleos et al. 2010; Rizzo et al. 2009). Also, Martinez et al. (2011) investigated the influences of operational parameters as the type of photocatalyst, presence of dissolved $\mathrm{O}_{2}$ or addition of $\mathrm{H}_{2} \mathrm{O}_{2}$ as co-oxidant, which affects DCF photocatalytic degradation. Mendez-Arriaga et al. (2008) and Calza et al. (2006) investigated photocatalytic degradation and transformation of DCF under the xenon arc lamp irradiation to assess influences of different operational parameters and identify intermediates. Peter Bartels reported that DCF concentration in river water decreases naturally due to sun light irradiation (Bartels and Tumpling 2007).

In our present work, titania-zirconia $\left(\mathrm{ZrO}_{2} / \mathrm{TiO}_{2}\right)$ nanocomposite catalyst was prepared by sol-gel method and was characterized. The photocatalytic efficiency of $\mathrm{ZrO}_{2} / \mathrm{TiO}_{2}$ nanocomposite for the degradation of DCF was investigated under operational parameters such as type of $\mathrm{ZrO}_{2} / \mathrm{TiO}_{2}$ nanocomposite, catalyst loadings, initial DCF concentrations and initial $\mathrm{pH}$ in batch process. LangmuirHinshelwood (L-H) kinetic model was employed to propose a rate equation of the photocatalytic degradation of DCF.

This present work was done at Department of Chemical Engineering, Indian Institute of Technology Kharagpur, India, and was completed in May 2012.

\section{Materials and methods}

Photocatalyst synthesis procedure

The $\mathrm{TiO}_{2} / \mathrm{ZrO}_{2}$ nanocomposite catalyst was prepared by sol-gel method. For the preparation of catalyst, titanium isopropoxide (Alfa Aesar, UK) and zirconium 
oxychloride octahydrate (Loba Chemic Pvt. Ltd., Mumbai, India) were the starting materials. Desired quantity of titanium isopropoxide and anhydrous ethanol was premixed for $45 \mathrm{~min}$ by stirring with a magnetic stirrer. Next, a certain amount of zirconium oxychloride octahydrate was dissolved in distilled water to form a solution. Under vigorous stirring, the solution is added dropwise into the previous mixture. Appropriate amount of hydrochloric acid (diluted) was added to adjust the $\mathrm{pH}$ of the solution to 2 . The temperature of the reaction system was maintained at $22{ }^{\circ} \mathrm{C}$ for slow hydrolysis. After $14 \mathrm{~h}$, the initial solution was transformed into an opaque sol, and the obtained sol was used as the precursor sol. The resultant sample was taken out and washed for several times by distilled water and absolute ethanol to remove excessive organic or inorganic impurities and then dried at $120^{\circ} \mathrm{C}$. Then, the composite powders are calcined at $500{ }^{\circ} \mathrm{C}$ in a furnace for $3 \mathrm{~h}$ (Jung and Park 2004). A series of samples with different mass ratio of $\mathrm{Zr} / \mathrm{Ti}$ are prepared with different $\mathrm{ZrO}_{2}$ content such as $6.3,11.8$ and $24.4 \mathrm{wt} \%$, and these were denoted by ZT-1, ZT-2 and ZT-3, respectively. $\mathrm{TiO}_{2}$ used as a base photocatalyst, and it was observed that effect of $\mathrm{ZrO}_{2}$ on the degradation is studied based on the variation of $\mathrm{Zi} / \mathrm{Ti}$ ratios. It was chosen based on the earlier literatures (Zhang and Zeng 2010).

\section{Catalyst characterization}

The composite catalysts were characterized by X-ray diffraction (XRD) (Philips PW183 system, Cu-K $\alpha$ radiation, transmission electron microscopy (TEM) (JEOL, JEM2100, Japan) and BET surface area analyzer (Quantachrome, AUTOSORB-1C, USA). The crystallographic information was established with powder XRD. TEM was used to determine the morphology and particle size of the samples. Specific surface area and pore volume of the calcined samples were determined by BET surface area analyzer.

\section{Experimental procedure}

The photocatalytic degradation of DCF (Sigma-Aldrich) was studied using $\mathrm{TiO}_{2} / \mathrm{ZrO}_{2}$ composite catalyst with different $\mathrm{Zr} / \mathrm{Ti}$ mass ratios. The reaction was carried out in a batch cylindrical glass vessel of 500-ml capacity having two coaxial cylinders, where the reaction was taken in the annular space and the UV source was placed at the center of the vessel. An 8-W ultraviolet lamp (Philips) with wavelength $218 \mathrm{~nm}$ was positioned inside a quartz tube. Air was bubbled to the reactor from the bottom. A typical reaction was carried out using $250 \mathrm{ml}$ solution of DCF of initial concentration $10 \mathrm{mg} / \mathrm{L}$ with $250 \mathrm{mg} / \mathrm{L}$ catalyst concentration at $30{ }^{\circ} \mathrm{C}$ with a variation of $\pm 1{ }^{\circ} \mathrm{C}$ and air flow rate of 0.25 LPM irradiated with an UV lamp. The samples were withdrawn at a time intervals of $30 \mathrm{~min}$ and analyzed by UV-VIS spectrophotometer (Chemito India Model 2600).

\section{Results and discussion}

\section{Characterization of catalysts}

The XRD patterns of $\mathrm{TiO}_{2} / \mathrm{ZrO}_{2}$ composites are shown in Fig. 1. It can be confirmed that $\mathrm{TiO}_{2}$ in "as-prepared samples" is identified as in anatase phase. The crystallite size was calculated from a diffraction plane of anatase, and the size is found to decrease with the increase in $\mathrm{ZrO}_{2}$ content. The degree of crystallinity of the particles depends on the amount of $\mathrm{ZrO}_{2}$ (Schiller et al. 2010). The XRD of catalysts has significant diffraction peaks representing the characteristics of the anatase phase of $\mathrm{TiO}_{2}$ and various $\mathrm{TiO}_{2} / \mathrm{ZrO}_{2}$ composite catalysts. The XRD of ZT- 1 shows a decrease in anatase phase compared with pure $\mathrm{TiO}_{2}$, but the weak tetragonal phase of $\mathrm{ZrO}_{2}$ shows the presence of zirconium. As the amount of $\mathrm{ZrO}_{2}$ increases from ZT-1 to ZT3, intensity of diffraction peak of $\mathrm{ZrO}_{2}$ increases, which suggests that $\mathrm{ZrO}_{2}$ is surface coupled with $\mathrm{TiO}_{2}$ in this composite photocatalyst although its content is low as well as the anatase form of $\mathrm{TiO}_{2}$ is recovered correspondingly. The XRD analysis indicates that, as the $\mathrm{ZrO}_{2}$ component increases, it prevents the phase transformations from anatase to rutile, which is favorable to the photocatalytic

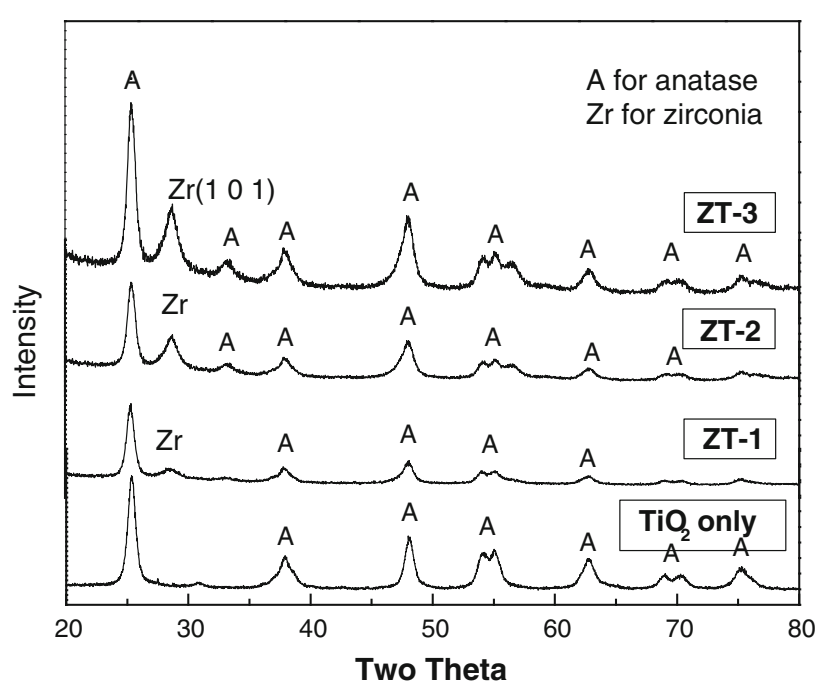

Fig. 1 XRD patterns of $\mathrm{TiO}_{2}$ and various $\mathrm{TiO}_{2} / \mathrm{ZrO}_{2}$ composite catalysts 
Fig. 2 TEM image of catalysts. a $\mathrm{TiO}_{2}$ only and $\mathbf{b} \mathrm{ZT}-2$
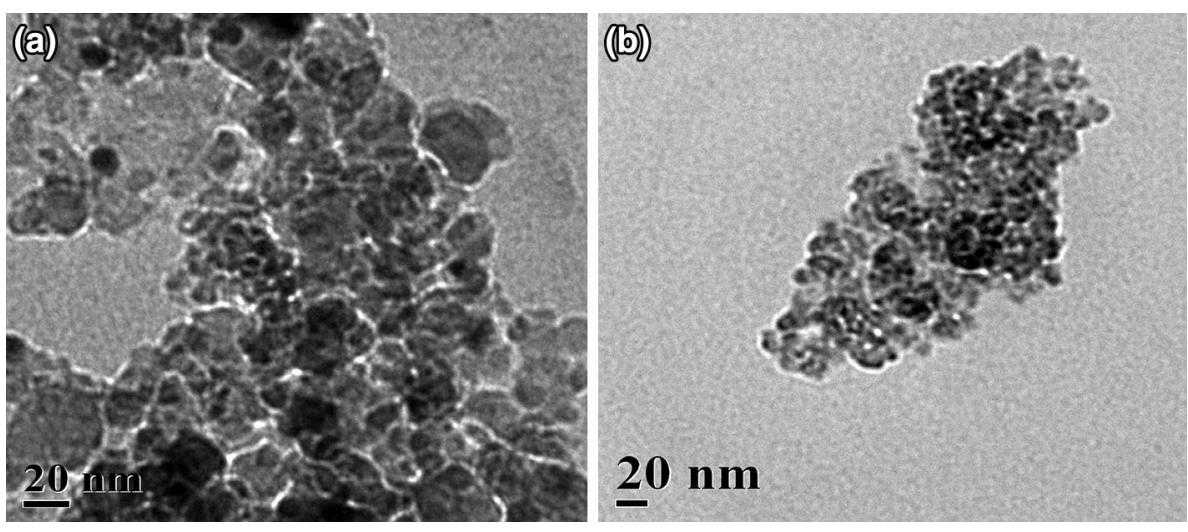

reaction since the anatase phase is known to have much higher activity than the rutile phase.

The morphology of nanocomposite particles is analyzed by TEM technique and shown in Fig. 2. From the figure, it is found that the particles are roughly spherical in shape, almost similar in size with narrow size distribution. The presence of macro voids and agglomeration of the particles are clear in the figure. From TEM micrograph, it is difficult to ascertain the presence of the particles of zirconium. It has been observed that the composite material is partly composed of clusters containing composite nanoparticles adhering to each other with a mean size of around $8 \mathrm{~nm}$ and size of $\mathrm{TiO}_{2}$ is roughly of $20 \mathrm{~nm}$. The figure also suggests that the incorporation of $\mathrm{ZrO}_{2}$ inhibits the growth of crystallites which leads to the smaller particle size with an increase in the amount of $\mathrm{ZrO}_{2}$ loading.

The catalysts were analyzed for BET, and the results are shown in Table 1. BET surface areas of $\mathrm{TiO}_{2} / \mathrm{ZrO}_{2}$ composites depend on the quantity of $\mathrm{ZrO}_{2}$. The largest surface area $\left(190 \mathrm{~m}^{2} / \mathrm{g}\right)$ and pore volume were observed for ZT-2. It has also been noticed that the pore volume increases with the content of $\mathrm{ZrO}_{2}$ up to ZT-2 and decreases in ZT-3 with further addition of more $\mathrm{Zr}^{4+}$. A decrease in surface area after high amount of $\mathrm{ZrO}_{2}$ could be noted that due to various factors such as penetration of the deposited active oxides into the pores of the support, thereby narrowing its pore volume, blocking some of the micropores and solidstate reaction between dispersed active oxides.

Table 1 BET surface area and pore volume data of various composite catalysts

\begin{tabular}{lll}
\hline Catalyst & $\mathrm{S}_{\mathrm{BET}}\left(\mathrm{m}^{2} / \mathrm{g}\right)$ & Pore volume $(\mathrm{ml} / \mathrm{g})$ \\
\hline$(\mathrm{ZT}-1)$ & 115 & 0.36 \\
$(\mathrm{ZT}-2)$ & 190 & 0.59 \\
$(\mathrm{ZT}-3)$ & 85 & 0.18 \\
$\mathrm{TiO}_{2}$ only & 110 & 0.29 \\
\hline
\end{tabular}

Selection of catalyst

The photocatalytic degradation of DCF was compared among different composite ZT-1, ZT-2 and ZT-3 prepared with various $\mathrm{TiO}_{2} / \mathrm{ZrO}_{2}$ mass ratio, and the results are shown in Fig. 3 by plotting percentage removal of DCF as a function of time. The results indicate that ZT-2 gives higher photocatalytic activity compared with other samples. The degradation of DCF is $92.41,81.42,70.68$ and $45.13 \%$ for ZT-2, ZT-1, $\mathrm{TiO}_{2}$ and ZT-3, respectively. The degradation depends on the BET surface area of the catalyst as the surface area also decreases in the order as ZT$2>\mathrm{ZT}-1>\mathrm{TiO}_{2}>\mathrm{ZT}-3$. It was also seen that the $\mathrm{ZrO}_{2}$ loading variation with $\mathrm{TiO}_{2}$ was effected the DCF removal (inset in Fig. 3). The percentage degradation is observed to increase with the increase in $\mathrm{ZrO}_{2}$ loading in $\mathrm{TiO}_{2} / \mathrm{ZrO}_{2}$

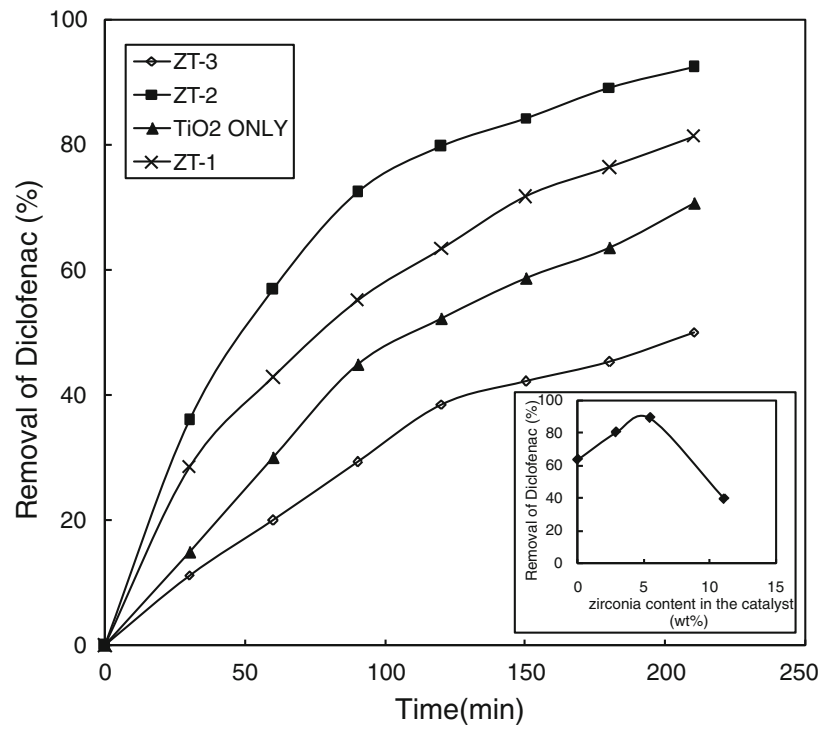

Fig. 3 Comparison of the percentage degradation of DCF by different $\mathrm{TiO}_{2} / \mathrm{ZrO}_{2}$ composite catalysts as well as $\mathrm{TiO}_{2}$ only. The inset represents the effect of zirconia content variation on DCF degradation 
composites, and it reaches to a maximum value at 5.49 for $11.8 \mathrm{wt} \%$ of zirconium (ZT-2), whereas beyond that value it decreases with the further increase of $\mathrm{ZrO}_{2}$ content. The decrease in degradation of DCF is due to the decrease in the anatase form in the composite and its porosity with the further addition of $\mathrm{ZrO}_{2}$ beyond $\mathrm{ZT}-2$. Therefore, the presence of excess $\mathrm{ZrO}_{2}$ in $\mathrm{TiO}_{2}$ could suppress the growth of $\mathrm{TiO}_{2}$ grains, and it may increase the surface area. It also decreases the anatase to rutile phase transformation and accelerates the surface hydroxylation.

\section{Effect of catalyst loading}

Quantitative variation of ZT-2 catalyst loading is an important parameter that can affect the degradation rate of DCF. As shown in Fig. 4, the effect of photocatalyst concentration on percentage removal of DCF was noted employing catalyst loading of $\mathrm{TiO}_{2} / \mathrm{ZrO}_{2}$ nanocomposite in the range of $50-500 \mathrm{mg} / \mathrm{L}$ at initial concentration of DCF $10 \mathrm{mg} / \mathrm{L}$. It can be observed that the initial degradation increases proportionally to catalyst concentration up to a certain limit of concentration, and after that, a slow increase in the removal is observed. This indicates a progressive saturation of the photonic absorption for a given incident radiation (Parra et al. 2002). At lower catalyst loading, much of light may be transmitted through the solution. However, higher reaction rate at a higher amount of catalyst loading may be explained in terms of complete utilization of incident photons striking on the catalyst surface and/or availability of active sites at the surface. So, the catalyst loading is a significant factor that can affect performance of photocatalysis.

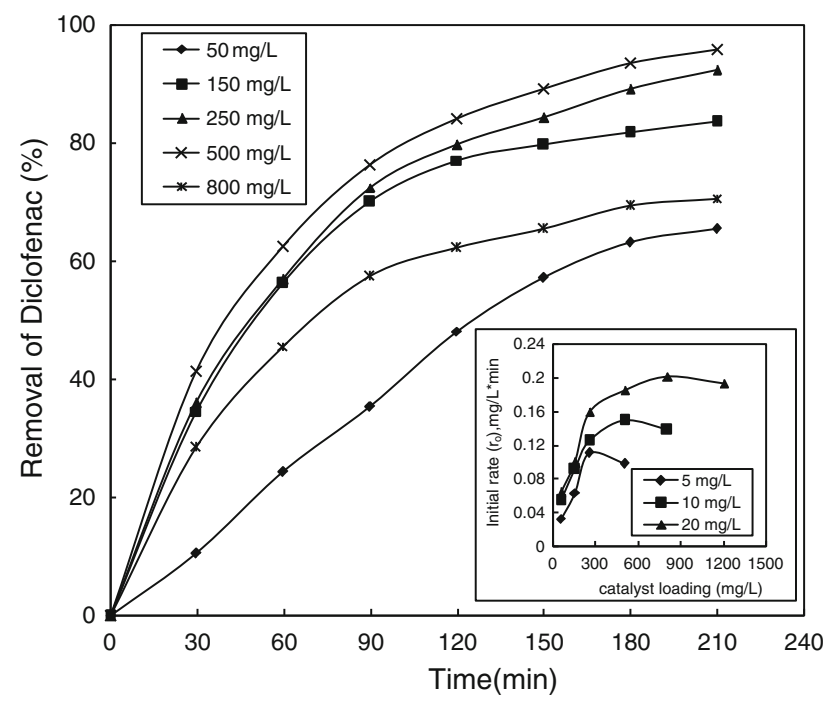

Fig. 4 Effect of catalyst concentration on DCF degradation: removal of diclofenac-time profiles and the inset represents initial rate versus catalyst loading at various initial concentration of DCF
Moreover, the rate of removal of DCF at different initial concentration of DCF is also a strong function of catalyst loading is inserted in Fig. 4.

The pseudo-first-order model equation is assumed as follows:

$-r_{A}=\mathrm{kC}^{n}$

The initial rate for the DCF photodegradation reaction with $\mathrm{TiO}_{2} / \mathrm{ZrO}_{2}$ composite catalysts has been fitted to a kinetic model, and the apparent rate constant $(k)$ has been determined for the different photocatalysts, since it enables one to estimate the photocatalytic activity of a catalyst.

The experimental data fitted well in the empirical equation, assuming the exponent ' $n$ ' of reactant concentration $C$ as unity. On integration,

$\ln \left[\frac{C_{0}}{C}\right]=\mathrm{kt}$

where $C_{0}$ and $\mathrm{C}$ are the initial and final concentration of DCF at time $t=0$ and $t=t$, where $\mathrm{t}$ is the irradiation time.

The initial reaction rate increases with increase in catalyst concentration from 5 to $20 \mathrm{mg} / \mathrm{L}$ of DCF concentration. Further, increase in catalyst concentration led to a decrease in rate. This maximum catalyst concentration, at which the rate is highest, is different for different DCF concentration. For example, the rate can be maximized at catalyst concentration $250 \mathrm{mg} / \mathrm{L}$ for DCF concentration of $5 \mathrm{mg} / \mathrm{L}$, whereas, for $20 \mathrm{mg} / \mathrm{L} \mathrm{DCF}$ concentration, maximum rate is observed at catalyst concentration of $800 \mathrm{mg} /$ L. With greater amount of catalyst, more is the turbidity; hence, it impedes the penetration of light in the reactor (Qamar and Muneer 2009), which in turn lowers the photocatalytic efficiency in the given working conditions. Another reason of decrease in rate may be due to the decrease in the portion of the irradiated surface of the catalyst particle due to the obstruction of light in the dense slurry.

\section{Effect of DCF concentration}

To investigate the effect of DCF concentration on the initial rate of degradation, at $5,10,20$ and $40 \mathrm{mg} / \mathrm{L}$ of DCF concentration for catalyst loading $250 \mathrm{mg} / \mathrm{L}, \ln \left(\mathrm{C}_{0} / \mathrm{C}\right)$ was plotted as a function of irradiation time as shown in Fig. 5 (inset). The plots show a good straight-line approximation, suggesting a first-order like dependence of degradation with respect to DCF concentration. The rate constants were obtained from the slopes of $\ln \left(\mathrm{C}_{0} / \mathrm{C}\right)$ versus time plots. Figure 5 shows the plot of the initial rate versus concentration of DCF, where it is interesting to note that the degradation rate increases with increase in DCF concentration from 5 to $20 \mathrm{mg} / \mathrm{L}$ and a further increase in concentration from 20 to $40 \mathrm{mg} / \mathrm{L}$ leads to no change in 


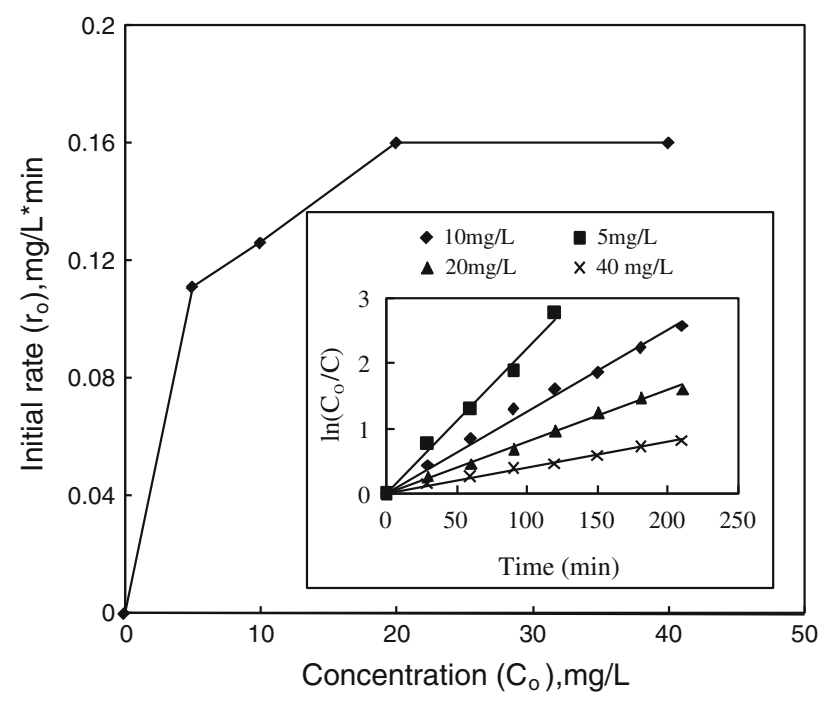

Fig. 5 Initial rate versus initial concentration of DCF solution and the inset shows linear transform in $\ln \left(C_{0} / C\right)$ as a function of time

degradation rate of the DCF. The reason for this can be explained by considering the formation of hydroxyl radicals in water due to irradiation. For a given irradiation sample and time, it can be expected that the production of $\mathrm{OH}$ radicals remains constant. Under such conditions, the extent of reaction between hydroxyl radicals and DCF molecules increases till $20 \mathrm{mg} / \mathrm{L}$. On further increase in concentration, the rate remains constant because the DCF concentration exceeds the concentration of hydroxyl radicals produced by water irradiation beyond $20 \mathrm{mg} / \mathrm{L}$. The amount of hydroxyl radicals produced at $20 \mathrm{mg} / \mathrm{L}$ DCF concentration is the optimum for that reaction condition.

Another reason of the dependability of the reaction rate may be the concentration of DCF increases, the availability of the photocatalyst surface does not increase, hence the generation of relative amounts of $\mathrm{OH}^{\bullet}$ and $\mathrm{O}_{2}{ }^{-}$on the surface of the catalyst becomes unchanged as the intensities of light, irradiation time and amount of catalyst remain constant.

\section{Effect of $\mathrm{pH}$}

An important parameter in the photocatalysis is the $\mathrm{pH}$ of solution, since it determines the surface charge properties of the photocatalyst and therefore the adsorption behavior of the pollutant. Figure 6 shows the percentage removal of DCF versus time under different $\mathrm{pH}$ ranging from 3 to 12 .

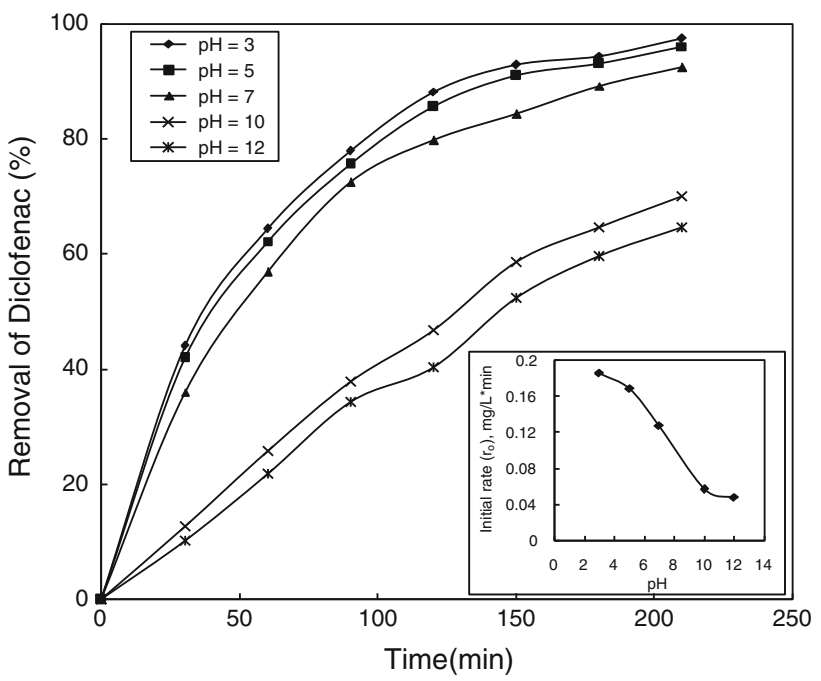

Fig. 6 Effect of pH on DCF percentage degradation: removal of diclofenac-time profiles and the inset presents initial rate versus $\mathrm{pH}$

The decline of the removal of DCF under different $\mathrm{pH}$ can be represented in the order $\mathrm{pH} 3>\mathrm{pH} 5>\mathrm{pH} 7>\mathrm{pH}$ $10>\mathrm{pH} 12$ at $210 \mathrm{~min}$. The initial rate of degradation of DCF as a function of time is plotted in Fig. 6 (inset). From Fig. 6, results are indicating that the degree of disappearance of DCF is strong in acidic conditions.

The possible explanation of this is the amphoteric behavior of semiconducting material and the change of the surface charge properties of $\mathrm{TiO}_{2} / \mathrm{ZrO}_{2}$ nanocomposite with the changes of $\mathrm{pH}$ values. The hypothetical explanation may be the presence of lone pairs of electrons on DCF molecules which induce electrostatic attraction between negatively charged DCF molecules and positively charged $\mathrm{TiO}_{2} / \mathrm{ZrO}_{2}$ composite in acidic condition and vice versa.

It is very difficult to elucidate the effects of $\mathrm{pH}$ on photodegradation activity due to the many possible reaction mechanisms; among them, the following three are predominant (Minero et al. 2000):

Catalyst $+\mathrm{hv}(\mathrm{UV}) \rightarrow$ catalyst $\left(\mathrm{e}^{-}+\mathrm{h}^{+}\right)$

$\mathrm{h}^{+}+\mathrm{OH}^{-} \rightarrow \mathrm{H}^{+}+\mathrm{OH}$

The water molecules react with positive hole and produce $\mathrm{OH}$

$\mathrm{h}^{+}+\mathrm{H}_{2} \mathrm{O} \rightarrow \mathrm{H}^{+}+\mathrm{OH}$

i) Hydroxyl radical attack:

$\mathrm{DCF}+\mathrm{OH} \rightarrow$ Degradation products 
ii) Oxidation by the positive hole:

$\mathrm{DCF}+\mathrm{h}^{+} \rightarrow$ Oxidation products

At low $\mathrm{pH}$, holes are considered as the major oxidizing species, while at neutral and high $\mathrm{pH}$, hydroxyl radicals are considered to be the major one. So, the influence of the $\mathrm{pH}$ on photocatalytic activity is dependent on substrate type and properties of $\mathrm{TiO}_{2} / \mathrm{ZrO}_{2}$ surface.

\section{Photodegradation kinetics of DCF}

The active sites on catalyst surface have the significant role in solid-catalyzed reaction. It can be observed from the previous literatures (Bangun and Adesina 1998; Chen and Jenq 1998) that the modified LangmuirHinshelwood $(\mathrm{L}-\mathrm{H})$ kinetic expression is successfully applied to analyze the heterogeneous photocatalytic reaction.

In the solid catalytic reaction in water, the surface of the $\mathrm{TiO}_{2} / \mathrm{ZrO}_{2}$ composite is always covered with the water molecules and there would exist a competition between water and DCF molecules for a single adsorption site. The active sites will be covered by DCF and water molecules, and the relation of the fraction of surface coverage with the initial concentration of DCF and water molecules can be expressed as (Fox and Dulay 1993):

$\theta=\frac{K_{\mathrm{DCF}} C_{0}}{\left(1+K_{\mathrm{DCF}} C_{0}+k_{w} C_{w}\right)}$

where $\theta$ is the fraction of surface covered by DCF molecules. $K_{\mathrm{DCF}}$ and $\mathrm{k}_{\mathrm{W}}$ are the adsorption equilibrium constant of DCF and water, respectively. $C_{0}$ and $C_{W}$ are the initial concentrations of DCF and water, respectively. $\theta$ may be written as,

$\theta=\frac{\left[\frac{K_{\mathrm{DCF}}}{1+k_{w} C_{w}}\right] C_{0}}{1+\left[\frac{K_{\mathrm{DCF}}}{1+k_{w} C_{w}}\right] C_{0}}$

The initial concentration of water $\left(C_{\mathrm{W}}\right)$ may be assumed to be constant during the reaction period. Therefore, $\theta$ is simplified introducing a new constant $K_{1}=\frac{K_{\mathrm{DCF}}}{1+k_{w} C_{w}}$. Equation 4 can be rewritten as

$\theta=\frac{K_{1} C_{0}}{1+K_{1} C_{0}}$

According to Langmuir-Hinshelwood $(\mathrm{L}-\mathrm{H})$, the rate of reaction $\left(-r_{\mathrm{A}}\right)$ is proportional to the fraction of surface covered by the substrate $(\theta)$ :
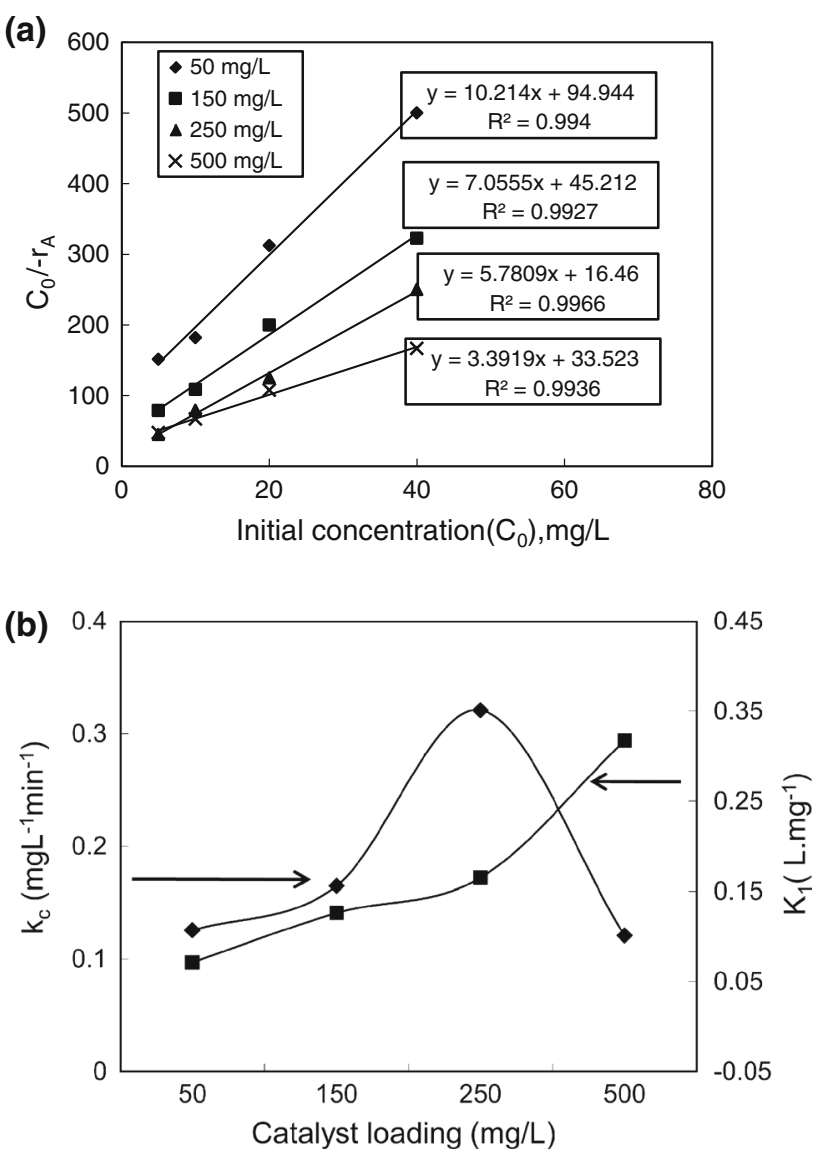

Fig. 7 a Relation between $C_{0} /-r_{\mathrm{A}}$ and $C_{0}$ at various catalysts loading and $\mathbf{b}$ the rate constant and the adsorption equilibrium constant $\left(K_{1}\right)$ (Diamond) as a function of catalyst loading

$-r_{A}=k_{c} \theta$

With Eq. (5) and Eq. (6), we get

$-r_{A}=\frac{K_{1} k_{c}\left[C_{0}\right]}{1+K_{1}\left[C_{0}\right]}$

Eq. (7) is linearized in the following form

$\frac{C_{0}}{-r_{A}}=\frac{1}{K_{1} k_{c}}+\frac{C_{0}}{k_{c}}$

The initial rate data were obtained from the slope of the tangent of the concentration profile at $t=0$. It was observed that these initial rates are closed to the values that are obtained by substituting the respective $C_{0}$ and $\mathrm{k}$ in Eq. (2). This initial rate data were fitted in Eq. (8) after transforming to their respective variable. A typical plot of $C_{0} /-r_{\mathrm{A}}$ versus $C_{0}$ at various catalysts loading is presented in Fig. 7a. 
At low concentrations of $5-40 \mathrm{mg} / \mathrm{L}$ of DCF, the rate data fitted to the linear equation satisfactorily with good correlation coefficients.

Dependence of $k_{\mathrm{c}}$ and the constant $K_{1}$ on catalyst loading is shown in Fig. $7 \mathrm{~b}$. It is observed that the rate constant $k_{\mathrm{c}}$ increases proportionally with increase in catalyst loading in the range $50-500 \mathrm{mg} / \mathrm{L}$, and it reaches to the value $0.351 \mathrm{mg} \mathrm{L}^{-1} \mathrm{~min}^{-1}$ at catalyst loading $250 \mathrm{mg} / \mathrm{L}$, which is maximum and then it decreases. However, $K_{1}$ increases gradually with increase in catalyst loading.

As mentioned in Fig. 4b, degradation rate depends on catalyst loading. Rate constant $\left(k_{\mathrm{c}}\right)$ seems to increase gradually with catalyst amount, which is supposed to become constant or decrease on further increment of catalyst amount by virtue of decrease in $K_{1}$. Constant $K_{1}$ decreases with increasing catalyst content, which may be due to the reduction in surface area. The decrease in surface area may be due to the possible agglomeration of catalyst particle at high quantity. It is obvious that the lower the amount of adsorbed substrate caused a lower degradation rate. It may be concluded that both pseudofirst-order and Langmuir-Hinshelwood type model can explain the rate kinetics of photodegradation of DCF using $\mathrm{TiO}_{2} / \mathrm{ZrO}_{2}$ catalyst.

\section{Conclusion}

The nanosized $\mathrm{TiO}_{2} / \mathrm{ZrO}_{2}$ photocatalytic materials are synthesized with sol-gel method followed by a suitable calcination treatment. The as-prepared $\mathrm{TiO}_{2} / \mathrm{ZrO}_{2}$ nanocomposites exhibit unique optical properties regarding to the absorption in the visible wavelength. The experimental results indicate that the $\mathrm{TiO}_{2} / \mathrm{ZrO}_{2}$ composites show a photocatalytic activity to degrade the organic pollutants such as DCF. The optimum mass ratio of $\mathrm{ZrO}_{2}$ on $\mathrm{TiO}_{2}$ is $11.8 \mathrm{wt} \%$. This composite shows higher photocatalytic activity than that of the commercially available $\mathrm{TiO}_{2}$ photocatalyst of anatase form. Reaction rate increases with increase in initial concentration of $\mathrm{DCF}$, and at a certain point, no change in degradation rate of the DCF was observed. DCF shows higher degradation rate in acidic condition, because adsorption on catalyst varies largely with the $\mathrm{pH}$ of the solution, which assigns to the strong dependence of surface-catalyzed reaction on $\mathrm{pH}$. The amount of catalysts may play a significant role upon the photoefficiency of the hybrid catalysts. Since the levels of DCF in environmental samples are relatively low, so the photocatalytic degradation at mild operating conditions is favorable in the water treatment including domestic applications. The kinetics of the photocatalytic degradation of DCF by $\mathrm{TiO}_{2} / \mathrm{ZrO}_{2}$ is fitted satisfactory to pseudo-first-order degradation kinetics as well as in modified LangmuirHinshelwood type model. This photocatalytic degradation is explained in terms of a model for the surface reaction between DCF and the oxidizing species $\mathrm{OH}$. The values the rate parameters $\left(k_{\mathrm{c}}\right.$ and $\left.K_{1}\right)$ depend on the amount of $\mathrm{TiO}_{2} / \mathrm{ZrO}_{2}$ composites catalyst. The present report involves new approaches in the development of $\mathrm{TiO}_{2} / \mathrm{ZrO}_{2}$ composite photocatalysts which can operate effectively under UV light irradiation in a water filter.

Acknowledgments The authors are thankful to Indian Institute of Technology Kharagpur, India, for providing infrastructure and resources.

\section{References}

Achilleos A, Hapeshi E, Xekoukoulotakis NP, Manztavinos D, FattaKassinos D (2010) Factors affecting diclofenac decomposition in water by $\mathrm{UV}-\mathrm{A} / \mathrm{TiO}_{2}$ photocatalysis. Chem Eng J 161(1-2): $53-59$

Akpan UG, Hameed BH (2009) Parameters affecting the photocatalytic degradation of dyes using $\mathrm{TiO}_{2}$-based photocatalysts: a review. J Hazard Mater 170(2-3):520-529

Akpan UG, Hameed BH (2010) The advancements in sol-gel method of doped- $\mathrm{TiO}_{2}$ photocatalysts. Appl Catal A Gen 375(1):1-11

Ashton D, Hilton M, Thomas KV (2004) Investigating the environmental transport of human pharmaceuticals to streams in the United Kingdom. Sci Total Environ 333(1-3):167-184

Bangun J, Adesina AA (1998) The photodegradation kinetics of aqueous sodium oxalate solution using $\mathrm{TiO}_{2}$ catalyst. Appl Catal A Gen 175(1-2):221-235

Bartels P, Tumpling W Jr (2007) Solar radiation influence on the decomposition process of diclofenac in surface waters. Sci Total Environ 374(1):143-155

Calza P, Sakkas VA, Medana C, Baiocchi C, Dimou A, Pelizzetti E, Albanis T (2006) Photocatalytic degradation study of diclofenac over aqueous $\mathrm{TiO}_{2}$ suspensions. Appl Catal B Environ 67(3-4):197-205

Chen PH, Jenq CH (1998) Kinetics of photocatalytic oxidation of trace organic compounds over titanium dioxide. Environ Int 24(8):871-879

Chen Y, Wang K, Lou L (2004) Photodegradation of dye pollutants on silica gel supported $\mathrm{TiO}_{2}$ particles under visible light irradiation. J Photoch Photobio A 163(1-2):281-287

Cho Y, Choi W, Haklee C, Hyeon T, Lee H (2001) Visible lightinduced degradation of carbon tetrachloride on dye-sensitized $\mathrm{TiO}_{2}$. Environ Sci Technol 35(5):966-970

Cunningham VL, Binks SP, Olson MJ (2009) Human health risk assessment from the presence of human pharmaceuticals in the aquatic environment. Regul Toxicol Pharm 53(1):39-45

Evgenidou E, Konstantinou I, Fytianos K, Albanis T (2006) Study of the removal of dichlorvos and dimethoate in a titanium dioxide 
mediated photocatalytic process through the examination of intermediates and the reaction mechanism. J Hazard Mater B 137(2):1056-1064

Fox MA, Dulay MT (1993) Heterogeneous photocatalysis. Chem Rev 93(1):341-357

Guettai N, Amar HA (2005) Photocatalytic oxidation of methyl orange in presence of titanium dioxide in aqueous suspension. Part I: Parametric study. Desalination 185(1-2):427-437

Henschel DB (1998) Cost analysis of activated carbon versus photocatalytic oxidation for removing organic compounds from indoor air. Air Waste Manage Assoc 48(10):985-994

Hoffmann MR, Martin ST, Choi W, Bahnemann DW (1995) Environmental applications of semiconductor photocatalysis. Chem Rev 95(1):69-96

Jacoby WA, Blake DM, Fennel JA, Boulter JE, Vargo LM, George MC, Dolberg SK (1996) Heterogeneous photocatalysis for control of volatile organic compounds in indoor air. Air Waste Manage Assoc 46(9):891-898

Jung KY, Park SB (2004) Photoactivity of $\mathrm{SiO}_{2} / \mathrm{TiO}_{2}$ and $\mathrm{ZrO}_{2} / \mathrm{TiO}_{2}$ mixed oxides prepared by sol-gel method. Mater Lett 58(22-23):2897-2900

Kaneco S, Katsumata H, Suzuki T, Ohta K (2006) Titanium dioxide mediated photocatalytic degradation of dibutyl phthalate in aqueous solution-kinetics, mineralization and reaction mechanism. Chem Eng J 125(1):59-66

Laoufi NA, Tassalit D, Bentahar F (2008) The degradation of phenol in water solution by $\mathrm{TiO}_{2}$ photocatalysis in a helical reactor. Global Nest J 10(3):404-418

Lee J, Ji K, Kho YL, Kim P, Choi K (2011) Chronic exposure to diclofenac on two freshwater cladocerans and Japanese medaka. Ecotox Environ Safe 74(5):1216-1225

Leztel M, Meztner G, Leztel T (2009) Exposure assessment of the pharmaceutical diclofenac based on long-term measurements of the aquatic input. Environ Int 35(2):363-368

Linsebigler AL, Lu G, Yates JT (1995) Photocatalysis on $\mathrm{TiO}_{2}$ surfaces: principles, mechanisms, and selected Results. Chem Rev 95(3):735-758

Martinez C, Canle LM, Fernandez MI, Santaballa JA, Faria J (2011) Aqueous degradation of diclofenac by heterogeneous photocatalysis using nanostructured materials. Appl Catal B Environ 107(1-2):110-118

Mendez-Arriaga F, Esplugas S, Gimenez J (2008) Photocatalytic degradation of non-steroidal anti-inflammatory drugs with $\mathrm{TiO}_{2}$ and simulated solar irradiation. Water Res 42(3):585-594

Minero C, Mariella G, Maurino V, Pelizzetti E (2000) Photocatalytic transformation of organic compounds in the presence of inorganic anions. 1. hydroxyl-mediated and direct electrontransfer reactions of phenol on a titanium dioxide-fluoride system. Langmuir 16(6):2632-2641

Naidoo V, Wolter K, Cuthbert R, Duncan N (2009) Veterinary diclofenac threatens Africa's endangered vulture species. Regul Toxicol Pharm 53(3):205-208

Parra S, Olivero J, Pulgarin C (2002) Relationships between physicochemical properties and photoreactivity of four biorecalcitrant phenylurea herbicides in aqueous $\mathrm{TiO}_{2}$ suspension. Appl Catal B Environ 36(1):75-85
Qamar M, Muneer M (2009) A comparative photocatalytic activity of titanium dioxide and zinc oxide by investigating the degradation of vanillin. Desalination 249(2):535-540

Qiu S, Starr TL (2007) Zirconium doping in titanium oxide photocatalytic films prepared by atomic layer deposition. J Electrochem Soc 154(6):472-475

Qourzal S, Barka N, Tamimi M, Assabbane A, Ait-Ichou Y (2008) Photodegradation of 2-naphthol in water by artificial light illumination using $\mathrm{TiO}_{2}$ photocatalyst: identification of intermediates and the reaction pathway. Appl Catal A Gen 334(1-2):386-393

Rizzo L, Meric S, Kassinos D, Guida M, Russo F, Belgiorno V (2009) Degradation of diclofenac by $\mathrm{TiO}_{2}$ photocatalysis: UV absorbance kinetics and process evaluation through a set of toxicity bioassays. Water Res 43(4):979-988

Schiller R, Weiss CK, Landfester K (2010) Phase stability and photocatalytic activity of $\mathrm{Zr}$-doped anatase synthesized in miniemulsion. Nanotechnology 21(40):405-419

Schmidt W, Rourke KO, Hernan R, Quinn B (2011) Effects of the pharmaceuticals gemfibrozil and diclofenac on the marine mussel (Mytilus spp.) and their comparison with standardized toxicity tests. Mar Pollut Bull 62(7):1389-1395

Shi-fu C, Geng-yu C (2003) $\mathrm{TiO}_{2}$ /beads as a photocatalyst for the degradation of $\mathrm{X}_{3 \mathrm{~B}}$ azo dye. J Environ Sci 15(1):83-87

Shi-fu C, Xue-li C (1998) Photocatalytic degradation of organocholine compounds using $\mathrm{TiO}_{2}$ supported on fiberglass cloth. J Environ Sci 10(4):433-436

Shulzt S, Baral HS, Charman S, Cunningham AA, Das D, Ghalsasi GR, Goudar MS, Green RE, Jones A, Nighot P, Pain DJ, Prakash $\mathrm{V}$ (2004) Diclofenac poisoning is widespread in declining vulture populations across the Indian subcontinent. Proc R Soc Lond B (Suppl) 271(6):458-460

Stasinakis AS (2008) Use of selected advanced oxidation processes (AOPs) for wastewater treatment-a mini review. Global Nest J 10(3):376-385

Stumpf M, Ternesa TA, Wilkena R, Rodrigues SV, Baumann W (1999) Polar drug residues in sewage and natural waters in the state of Rio de Janeiro, Brazil. Sci Total Environ 225(1-2):135-141

Ternes TA (1998) Occurrence of drugs in German sewage treatment plants and rivers. Water Res 32(11):3245-3260

Tian-hua X, Chen-lu S, Yong L, Gao-rong H (2004) Band structures of $\mathrm{TiO}_{2}$ doped with $\mathrm{N}, \mathrm{C}$ and $\mathrm{B}$. J Zhejiang Univ Sci B 7(4):299-303

Venkatachalam N, Palanichamy M, Arabindoo B, Murugesan V (2007) Enhanced photocatalytic degradation of 4-chlorophenol by $\mathrm{Zr}^{4+}$ doped nano $\mathrm{TiO}_{2}$. J Mol Catal A Chem 266(1-2):158-165

Vishwanathan V, Roh H, Kim J, Jun K (2004) Surface properties and catalytic activity of $\mathrm{TiO}_{2}-\mathrm{ZrO}_{2}$ mixed oxides in dehydration of methanol to dimethyl ether. Catal Lett 96(1-2):23-28

Wang K, Hsieh Y, Wu C, Chang C (2000) The pH and anion effects on the heterogeneous photocatalytic degradation of o-methylbenzoic acid in $\mathrm{TiO}_{2}$ aqueous suspension. Chemosphere 40(4):389-394 
Wang Y, Liu S, Lu M, Wang S, Gu F, Gai XZ, Cui XP, Pan J (2004) Preparation and photocatalytic properties of $\mathrm{Zr}^{4+}$-doped $\mathrm{TiO}_{2}$ nanocrystals. J Mol Catal A Chem 215(1-2):137-142

Wv J, Chung C, Ay C, Wang I (1984) Non-oxidative dehydrogenation of ethylbenzene over $\mathrm{TiO}_{2}-\mathrm{ZrO}_{2}$ catalysts. J Catal 87(1):98-107

Zaleska A (2008) Doped- $\mathrm{TiO}_{2}$ : a Review. Recent pat Eng 2(3):157-164
Zhang D, Zeng F (2010) Structural, photochemical and photocatalytic properties of zirconium oxide doped $\mathrm{TiO}_{2}$ nanocrystallites. Appl Surf Sci 257(3):867-871 